\title{
Unemployment Rates and Trauma Admissions
}

\author{
Atul K. Madan · Julie Sapozhnik · Areti Tillou • \\ Aml Raafat · Norman E McSwain
}

Published online: 3 August 2007

(C) Société Internationale de Chirurgie 2007

\begin{abstract}
In this article, we tested the hypothesis that the number and demographic characteristics of admissions to our trauma center were related to unemployment rates. The correlation study was conducted at The American College of Surgeons-verified level I trauma center in our area (New Orleans, Louisiana). It included all trauma admissions. Monthly unemployment rate data from our area were obtained from the Bureau of Labor Statistics. The hospital trauma registry supplied trauma emergency room admissions and demographic data. Mean daily trauma admissions were calculated for each month. Pearson correlations were used for statistical analysis. Over 24,000 trauma admissions occurred over a six-year period. Unemployment rates correlated with penetrating trauma admissions $(r=0.50 ; p<0.001)$. Interestingly, unemployment rates inversely correlated with total trauma admissions $(r=-0.73 ; p<0.001)$, blunt trauma
\end{abstract}

A. K. Madan $(\bowtie)$

Department of Surgery, University of Tennessee Health Science Center, 956 Court Avenue, Room G210, Memphis, Tennessee 38163, USA

e-mail: amadan@utmem.edu

\section{J. Sapozhnik}

Department of Anesthesiology, Northwestern University, Chicago, Illinois, USA

A. Tillou

Department of Surgery, University of California at Los Angeles, Los Angeles, California, USA

A. Raafat

Department of Surgery, Henry Ford Hospital, Detroit, Michigan, USA

N. E McSwain

Department of Surgery, Tulane University, New Orleans,

Louisiana, USA admissions $(r=-0.81 ; p<0.001)$, and ratio of blunt-to-penetrating trauma admissions $(r=-0.82 ; p<0.001)$. Higher percentage of male patients $(r=0.66 ; p<0.001)$, percentage of African-American patients $(r=0.53 ; p<0.001)$, and mortality $(r=0.56 ; p<0.001)$ correlated positively with higher unemployment rates. We concluded that as unemployment rates decrease, emergency room penetrating trauma admissions decrease, while total and blunt trauma admissions increase. As the socioeconomic status (measured by unemployment rates) of the community changes, so do the demographic make-up and mortality of the trauma population. Our findings suggest that during times of economic hardships, certain population groups are at higher risk for trauma. Prevention should be aimed accordingly.

The relationship between socioeconomics and trauma has not been fully investigated. Very few studies have examined this relationship in the literature. Since socioeconomics has a direct impact on individual lives, it very likely impacts the amount and type of trauma that occurs in a community. It has already been shown that other social factors such as substance use are related to trauma [1,2]. Therefore, it is not inappropriate to speculate that socioeconomics plays a role in the number and demographics of trauma admissions. We decided to use unemployment rates as a surrogate measure for socioeconomics of our community. Herein we tested the hypothesis that the number and demographic characteristics of admissions to our trauma center were related to unemployment rates.

\section{Materials and methods}

We performed this study using two separate databases. One database was the Medical Center of Louisiana at New 
Table 1 Average monthly trauma admissions and unemployment rate

\begin{tabular}{lll}
\hline & Mean & Range \\
\hline Penetrating admissions & 101 & $(53-137)$ \\
Blunt admissions & 229 & $(136-337)$ \\
Ratio of blunt-to-penetrating admissions & 2.2 & $(1.2-5.2)$ \\
Total admissions & 330 & $(232-451)$ \\
Unemployment rate & 5.8 & $(3.5-8.4)$ \\
\hline
\end{tabular}

Orleans (Charity Hospital) trauma registry, which was accessed with permission of our Institutional Review Board. Our trauma center is the only one of two American College of Surgeons-verified level I trauma center in Louisiana. The next closest trauma center is located 450 miles north of ours. The unemployment rate data for the New Orleans metropolitan area was obtained from the Bureau of Labor Statistics database that was online.

Emergency room trauma admission and demographics of trauma patients were obtained from the trauma registry for the period from January 1994 to November 1999. Mean daily trauma admissions were calculated for each month. Data such as ratio of blunt-to-penetrating trauma, blunt trauma admissions, penetrating trauma admissions, gender, ethnicity, and mortality were collected. The daily ratio of blunt-to-penetrating trauma, blunt trauma admissions, and penetrating trauma admissions were calculated. Mortality included all deaths, whether in the emergency room or in those that were admitted. Monthly gender percentage, ethnic percentage, and mortality rates were also computed. Pearson's correlations were used for statistical analysis (GraphPad InStat version 3.05, San Diego, CA). Unemployment rates were correlated with total number of trauma admissions, type of trauma, gender of trauma admissions, ethnicity of trauma admissions, and mortality rates.

\section{Results}

There were 24,265 trauma admissions at the Medical Center of Louisiana at New Orleans (Charity Hospital) during our six-year period of the investigation (January 1994 to November 1999). Complete data were found for 23,446 patients. Missing data such as cause of injury, mortality, and demographic data were reasons for excluding some of the patients.

Table 1 displays the mean daily trauma admission rate per month and the range. Average mortality and demographics are given in Table 2 .

Unemployment rates correlated with the number of penetrating trauma admissions as demonstrated in Figure $1(r$
Table 2 Average monthly percentage of gender, ethnicity, and mortality

\begin{tabular}{lll}
\hline & Average & Range \\
\hline Male & $76 \%$ & $(67-82 \%)$ \\
African American & $68 \%$ & $(56-77 \%)$ \\
Mortality & $6 \%$ & $(2-10 \%)$ \\
\hline
\end{tabular}

Unemployment Rates versus Penetrating Trauma Admissions

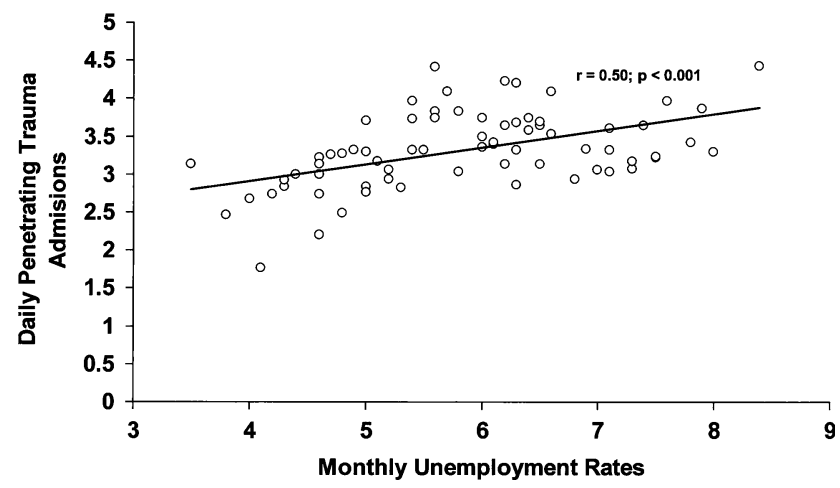

Fig. 1 Monthly unemployment rates (\%) had a positive correlation with daily penetrating trauma admission rates

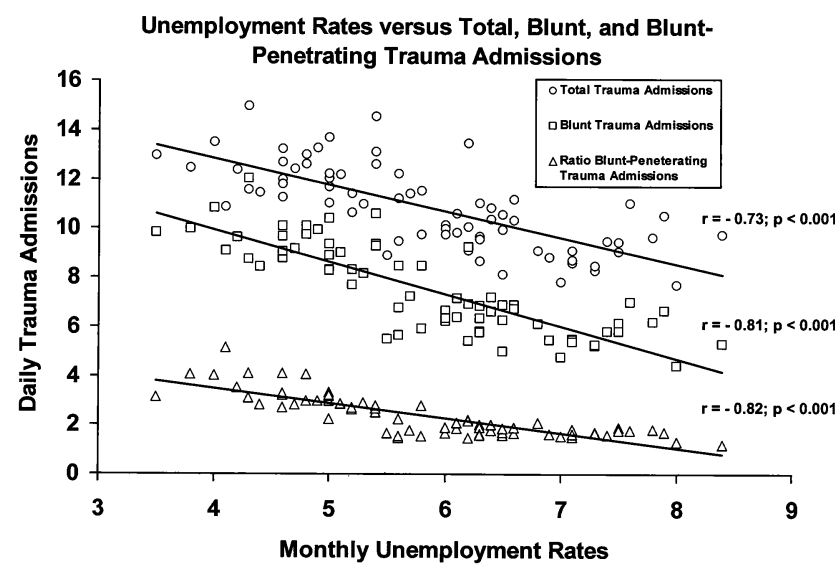

Fig. 2 There was a negative correlation between daily total, blunt, and ratio of blunt-to-penetrating trauma admission rates and monthly unemployment rates $(\%)$

$=0.50 ; p<0.001)$. On the other hand, unemployment rates inversely correlated with total trauma admissions $(r=-$ $0.73 ; p<0.001)$, blunt trauma admissions $(r=-0.81 ; p<$ 0.001 ), and ratio of blunt-to-penetrating trauma admissions $(r=-0.82 ; p<0.001)$, as displayed in Figure 2. An increased percentage of male patients $(r=0.66 ; p<0.001)$ and African-Americans $(r=0.53 ; p<0.001)$ was noted during periods of higher unemployment (Fig. 3). Furthermore, Figure 4 shows an increase in mortality rates correlating directly with higher unemployment rates. 


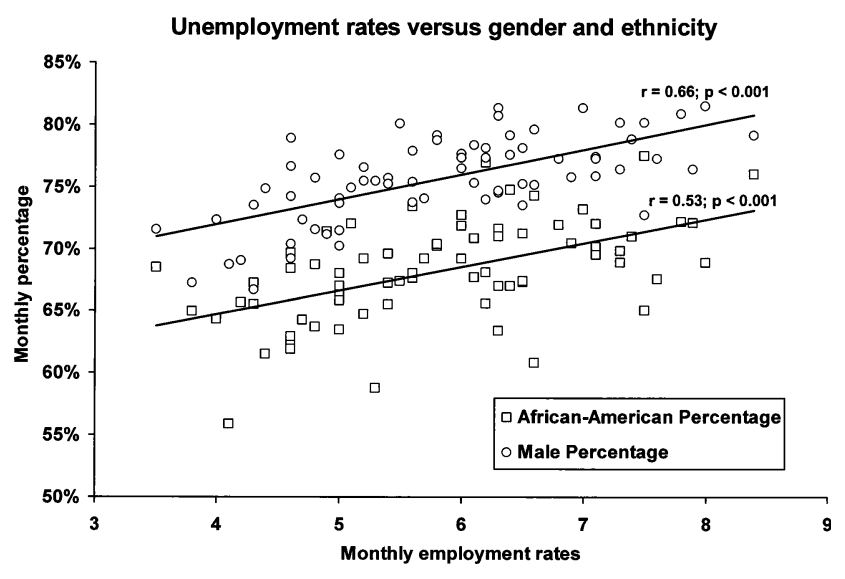

Fig. 3 Monthly African-American and male percentages had positive correlation with monthly unemployment rates $(\%)$

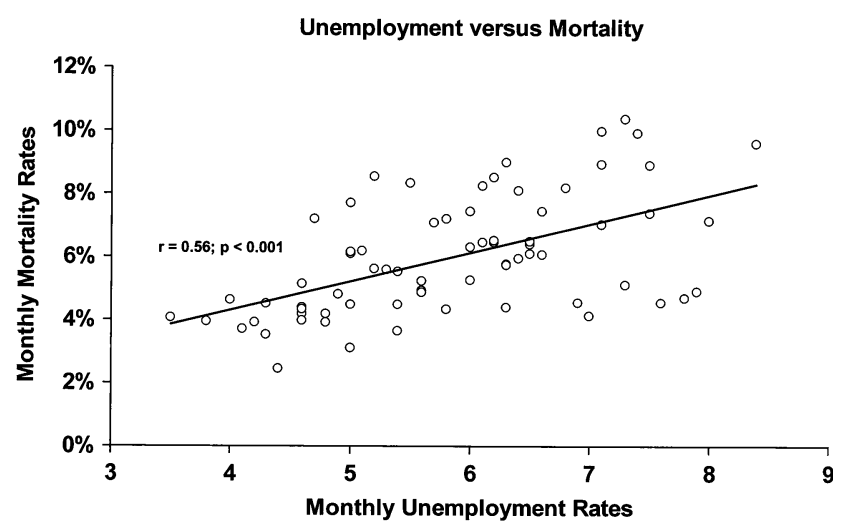

Fig. 4 Monthly unemployment rates (\%) positively correlated with monthly mortality rates

\section{Discussion}

Our data demonstrate that a decrease in the unemployment rate was associated with a decrease in emergency room penetrating trauma admissions but with an overall increase in total trauma admissions and blunt trauma admissions. In addition, there was a change in patient demographics as unemployment rates changed. More male patients and African-American patients were victims of trauma when unemployment rates were high. It would have been interesting to note how the specific unemployment rates of African-American patients and male patients correlated with trauma admissions. Unfortunately, we do not have these data. Our assumption is that these two groups were adversely affected by the unemployment rates either directly or indirectly. A limitation of our study is that our information was from the 1990s. More recent information was not available.

Interestingly, mortality rates correlated directly with unemployment rates. Our belief is that this represents more severe injury during times of higher unemployment rates.
This suggests that although total trauma admissions may decrease during times of high unemployment rates, more severe trauma may be occurring. This is likely because of the increase in penetrating trauma.

While no other study has specifically looked at trauma admissions and unemployment rates, there have been some studies that have addressed socioeconomic factors [3-12]. Ben-Shlomo et al. [3] demonstrated that there was a strong relationship between all-cause mortality and the population characteristics of the area in which one lived. Although this study was not done in the United States so its results may not be generalizable to our population, it supports the assumptions that socioeconomics do affect trauma mortality.

Another study demonstrated that unemployment affected changes in drinking while driving and the frequency of motor vehicle collisions [4]. Kerr et al. [5] concluded that unemployed patients were more likely to have accidents related to alcohol than employed patients. Our previous studies have shown that alcohol and drug use is directly related to interpersonal violence $[1,2]$. It is not surprising that substance use, motor vehicle collisions, violent trauma, and unemployment rates are all related. For example, a decrease in one's income could lead to more risk-taking behaviors. Risktaking behaviors are more likely to be related to substance use and trauma. Another study performed in the United States indicated that there was a relationship between unemployment and victims of violent trauma [6]. Those patients who knew their assailants were more likely to be unemployed. Other studies have demonstrated that socioeconomic factors are related to burn rates as well $[7,8]$.

There is significant evidence that demonstrates that socioeconomic factors are related to childhood injuries [912]. One Canadian study has demonstrated a consistent relationship between lower socioeconomic status and injury rates [11]. These studies in the pediatric population demonstrated that lower-income patients (lower-income households, higher unemployment rates, lower median income, and lower percentage of healthcare coverage) were associated with greater incidence of childhood injuries [9, 10, 12]. More studies should examine the relationship between trauma rates and unemployment rates. Currently, no literature exists investigating this relationship. It is interesting and surprising that increased trauma was seen with improved economy. This may be due to the fact that more discretionary income leads to more travel and more motor vehicle collisions. The reverse also could be true: that more tourism to our area caused more motor vehicle collisions and that increased tourism caused more employment. While most of our blunt trauma was motor vehicle collisions, we did not examine specific data to compare motor vehicle collisions to unemployment rates.

Our data suggest that unemployment rates affect trauma admissions and demographics. It is difficult to estab- 
lish a causal relationship when examining such factors that have multiple confounding factors. Further studies are required to determine what changes in public policy should be made. From our data it seems that economic growth may be a useful strategy to help prevent penetrating trauma. Injury prevention efforts targeted at economically disadvantaged populations and high-risk groups should be stressed when designing community trauma outreach programs, especially during times of economic hardships.

Acknowledgments The authors acknowledge the technical assistance of Mrs. Courtney Bishop in the preparation of this article.

\section{References}

1. Madan AK, Beech DJ, Flint LM (2001) The association between substance use and injury due to interpersonal violence. J Ped Surg 36(3):440-442

2. Madan AK, Yu K, Beech DJ (1999) Alcohol and drug use in victims of life-threatening trauma. J Trauma 47(3):568-571

3. Ben-Shlomo Y, White IR, Marmot M (1996) Does the variation in the socioeconomic characteristics of an area affect mortality? BMJ 312:1013-1014
4. Mercer GW (1987) Influences on passenger vehicle casualty accident frequency and severity: unemployment, driver gender, driver age, drinking driving and restraint device use. Accid Anal Prev 19(3):231-236

5. Kerr MH, Campbell FC, Rutherford WH (1987) Unemployment, alcohol and injury in west Belfast. Injury 18(5):313-314

6. Yancey AH, Gabel-Hughes KS, Ezell S, et al. (1994) The relationship between violent trauma and nonemployment in Washington, DC. J Natl Med Assoc 86(9):661-666

7. Locke JA, Rossignol AM, Boyle CM, et al. (1986) Socioeconomic factors and burn rates in persons hospitalized for burns in Massachusetts. Public Health Rep 101(4):389-395

8. Locke JA, Rossignol AM, Burke JF (1990) Socioeconomic factors in the incidence of hospitalized burn injuries in New England countries, USA. Burns 16(4):273-277

9. Pomerantz WJ, Dowd MD, Buncher CR (2001) Relationship between socioeconomic factors and severe childhood injuries. J Urban Health 78(1):141-151

10. Durkin M, Davidson LL, Kuhn L, et al. (1994) Low-income neighborhoods and the risk of severe pediatric injury: a smallarea analysis in northern Manhattan. Am J Public Health 84(4):587-592

11. Faelker T, Pickett W, Brison RJ (2000) Socioeconomic differences in childhood injury: a population based epidemiologic study in Ontario, Canada. Inj Prev 6(3):203-208

12. Overpeck MD, Jones DH, Trumble AC, et al. (1997) Socioeconomic and racial/ethnic factors affecting non-fatal medically attended injury rates in US children. Inj Prev 3(4):272-276 